ology of the lesion and suggests either trauma or infection, both of which are likely to subside. Hoefnagel and Penry $y^{4}$ presented six cases of seventh nerve paresis, three of which spontaneously improved. Patient S. Mc., whose facial nerve paresis has persisted, has associated left mild hemiparesis and minor motor seizures. This suggests a more central etiology of his neurologic lesion.

The purpose of this communication is not only to corroborate the findings of Dr. Cayler, but to caution against the assigning of a single etiology to this combination of lesions.

William B. Strong, M.D.

Daniel R. Silbert, M.D.

Department of Pediatric Cardiology Babies and Childrens Hospital

Case Western Reserve University School of Medicine Cleveland, Ohio 44106

\section{REFERENCES}

1. Cayler, G. G.: An "epidemic" of congenital facial paresis and heart disease, Pediatrics 40:666, 1967.

2. Cayler, G. G.: Additional cases of a cardiofacial syndrome, J. Pediat. 73:953, 1968.

3. Marino, H.: Paralysis of muscles of the chin, surgical treatment, Surg. Gynec. \& Obst. $96: 433,1953$.

4. Hoefnagel, D., and Penry, I. K.: Partial facial paralysis in young children, New England J. Med. 262:1126, 1960

\title{
Growth hormone levels in children with congenital heart disease
}

The association of congenital heart disease (CHD) and decreased linear growth is well known, ${ }^{1,2}$ but a causal relationship has not yet been established. Linde and associates ${ }^{2}$ observed the greatest retardation in patients with cyanotic CHD, but height could not be further correlated with the degree of cyanosis. He explored several possible etiologies, but concluded that neither tissue anoxia, infection, pulmonary hypertension, nor poor nutrition were responsible for the impaired growth in CHD.

The possibility that children with short stature and CHD have decreased levels of serum human growth hormone (HGH) has not been previously investigated. Conceivably, impaired circulation in the area of the pituitary gland secondary to CHD might result in diminished pituitary acidophilic function.

Subjects for the present study were 107 patients ( 57 males and 50 females, aged 2 to 18 years) with CHD being followed by the Pediatric Cardiology Section, University of Michigan Medical Center. Diagnoses varied, but all children were inpatients admitted for cardiac catheterization. They were classified according to height, and by the presence or absence of cyanosis. Fasting serum samples for HGH assay were obtained the day of, but prior to, catheterization. HGH determinations were performed by a radioimmunoassay method previously described in detail. ${ }^{3}$

Seventy-three patients with heights below the fiftieth percentile ${ }^{4}$ had a mean $\mathrm{HGH}$ level of 8.5 $\mathrm{m} \mu \mathrm{g}$ per milliliter with a median value of 5.6 ; the 34 children with heights above the fiftieth percentile had a mean HGH of 6.1 and median of 3.9. Of the subjects in the shortest group, 34 were below the tenth percentile in height; mean and median $\mathrm{HGH}$ levels for these children were 6.5 and 4.1 , respectively.

Thirteen of the patients were cyanotic and had mean and median HGH levels of 8.3 and $4.8 \mathrm{~m} \mu \mathrm{g}$ per milliliter. The remaining children with noncyanotic CHD had mean and median values of 7.6 and 5.2, respectively.

Calculation of standard deviations was not appropriate because the data tended to be skewed to the right. However, nonparametric analysis using chi-square revealed no significant difference between the HGH medians of any of the groups whether divided by height or by presence or absence of cyanosis.

This study again confirms the association of CHD and impaired growth: 68 per cent of the patients were below the fiftieth percentile for height, and 32 per cent were below the tenth percentile. However, there was no positive correlation between height and fasting HGH. It is possible that some patients may have shown a diminished $\mathrm{HGH}$ response if the insulin or arginine provocative test had been performed. On the other hand, it has been suggested that a fasting $\mathrm{HGH}$ level of $6.0 \mathrm{~m} \mu \mathrm{g}$ per milliliter or more is probably indicative of normal growth hormone responsiveness even in the absence of further studies. ${ }^{5}$ Forty-nine per cent of the patients with heights below the fittieth percentile fell into this category compared to 38 per cent of the larger children. Thus, it seems likely that the same conclusion might have been reached had more elaborate studies been performed. Finally, the few children with cyanotic CHD had HGH levels comparable to the acyanotic group, suggesting that HGH production may be relatively indifferent to decreased oxygen saturation of the blood. 
In summary, fasting HGH levels in a large group of children with $\mathrm{CHD}$ did not appear to correlate with height percentile. Whatever mechanism may be responsible for the decreased growth of patients with $\mathrm{CHD}$ is not manifested by diminished levels of $\mathrm{HGH}$ in the fasting state.

George E. Bacon, M.D.

Burton L. Perry, M.D. George H. Lowrey, M.D. Mechthilde Knoller Department of Pediatrics University of Michigan Ann Arbor, Mich.

\section{REFERENCES}

1. Mehrizi, A., and Drash, A.: Growth disturbance in congenital heart disease, J. Pediat. 61:418, 1962.

2. Linde, L. M., Dunn, O. J., Shireson, R., and Rasof, B.: Growth in children with congenital heart disease, J. Pediat. 70:413, 1967.

3. Knoller, M., Taso, M. U., and Lowrey, G. H.: Radio immunoassay of human growth hormone, Clin. Chem. 14:145, 1968.

4. Reed, R. B., and Stuart, H. C.: Patterns of growth in height and weight from birth to eighteen years of age, Pediatrics 24:904, 1959.

5. Frohman, L. A., Aceto, T., Ir., and MacGillivray, M. H.: Studies of growth hormone secretion in children: normal, hypopituitary, and constitutionally delayed, J. Clin. Endocrinol. 27:1409, 1967 .

\section{Hemodynamic alterations produced by prolonged urethane anesthesia in the intact dog}

When studying hemodynamic phenomena in anesthetized animals, the choice of the anesthetic agent is of paramount importance. The time course of hemodynamic alterations produced by the anesthetic and the metabolic effects as well as the influence on the phenomena being tested must be carefully assessed. Urethane is a commonly used anesthetic in animal experiments. However, little has been recorded in the literature on the hemodynamic effects of prolonged urethane anesthesia alone in intact animals. The effects become more important as experimental designs become more complex. Thus, studies were conducted by us to learn the hemodynamic alterations produced by prolonged urethane anesthesia in the intact dog. These studies were necessary for proper evaluation and interpretation of physiologic data.

Five mongrel dogs, averaging 16.4 kilograms, were anesthetized with 1.5 to $2.0 \mathrm{Gm}$. per kilogram of urethane (ethyl carbamate). Catheters were

Table I. The time course of hemodynamic phenomena in intact dogs anesthetized with urethane (average values for 5 dogs)

\begin{tabular}{|c|c|c|c|c|c|c|c|c|c|c|}
\hline $\begin{array}{c}\text { Time after } \\
\text { induction of } \\
\text { anesthesia } \\
\text { (hr.) }\end{array}$ & $\begin{array}{c}F A \\
(m m . \\
H g)\end{array}$ & $\begin{array}{c}P V S \\
(\mathrm{~mm} . \\
H g)\end{array}$ & $\begin{array}{c}L A \\
(m m . \\
H g)\end{array}$ & $\begin{array}{c}P A \\
(m m . \\
H g)\end{array}$ & $\begin{array}{c}R A \\
(m m . \\
H g)\end{array}$ & $\begin{array}{l}\text { C.I. } \\
(c . c . / \\
K g .)\end{array}$ & $\begin{array}{l}P B V \\
(c . c . / \\
K g .)\end{array}$ & $\begin{array}{c}H R \\
\text { (beats/ } \\
\text { min.) }\end{array}$ & $\left|\begin{array}{c}R R \\
\text { (breaths } \\
\text { min. })\end{array}\right|$ & $\begin{array}{l}S V \\
\text { (c.c.f } \\
\text { beat) }\end{array}$ \\
\hline 1.0 & 132 & - & - & - & -- & 190 & - & 136 & - & 22.7 \\
\hline 1.5 & 130 & 10.7 & 3.6 & 16.7 & +2.4 & 185 & 9.20 & 152 & 36 & 19.4 \\
\hline 2 & 127 & 9.0 & 2.7 & 16.6 & +1.2 & 168 & 8.81 & 158 & 40 & 18.0 \\
\hline 2.5 & 124 & 8.6 & 1.5 & 14.9 & -0.6 & 151 & 6.38 & 156 & 35 & 16.3 \\
\hline 3 & 120 & 5.9 & 1.7 & 14.6 & +0.2 & 138 & 10.66 & 153 & 36 & 14.6 \\
\hline 3.5 & 115 & 4.5 & 0.7 & 13.4 & -0.8 & 118 & 9.71 & 158 & 36 & 11.8 \\
\hline 4 & 112 & 4.3 & -0.2 & 13.0 & -0.2 & 103 & 10.08 & 168 & 40 & 10.5 \\
\hline 4.5 & 120 & 5.1 & -1.4 & 12.8 & -0.7 & 113 & 10.28 & 170 & 35 & 10.5 \\
\hline 5 & 111 & 6.3 & -0.7 & 12.8 & -1.4 & 100 & 9.44 & 165 & 38 & 9.5 \\
\hline
\end{tabular}

Abbreviations: FA, Femoral artery; PVS, small pulmonary vein; LA, left atrium; PA, pulmonaty artery; RA, right atrium; C.I., cardiac index; $P B V$, pulmonary blood volume; $H R$, heart rate; $R R$, respiratory rate; $S V$, stroke volume. 